\title{
A Study on Mobile Language Learning Strategy of Non-English Majors in a Chinese Private University
}

\author{
Yongjin $\mathrm{Zhu}^{1 *}$, Han $\mathrm{Cheng}^{2}$, Kaxi $\mathrm{Hu}^{2}$ \\ ${ }^{1}$ College of Foreign Studies Hubei Normal University, Huangshi 435002, Hubei, China. E-mail: yj.zhu@hbnu.edu.cn \\ ${ }^{2}$ College of Literature and Science, Hubei Normal University, Huangshi 435002, Hubei, China.
}

Fund Project: The paper is supported by Hubei Normal University Funds (NO: HS2020QN002); College of Literature and Science, Hubei Normal University Funds (NO: 202004); Chinese students innovation and Entrepreneurship Funds (NO: 202013256001).

Abstract: This quantitative study investigated the mobile language learning strategy of non-English major students among a Chinese private university. A total 107 students were selected and the results showed that the students had a moderate level of mobile language learning strategy and in each sub-strategy. No significant difference was found in the uses of language strategy between the male and female students.

Keywords: Mobile Language Learning Strategy; Private University; Difference

\section{Introduction}

Language learning strategy is a deliberate, goal-directed attempt to manage and control efforts to learn a foreign or second language(Oxford, 1990). Rubin (2011) claimed language learning strategies are learners with the target language to develop language knowledge and social language skills. The strategy is best used to refer to the general trend of language learners using the general trend or general characteristics of the method which is used to describe the specific form of visual behavior. (Oxford, 1995) Cohen () argues that language learning strategies refer to learners' conscious or semi-conscious behavior and mental activity, and they have clear goals. Therefore, the learning strategy should be a combination of psychological cognitive process and specific behavior of the dynamic system, which is also the integrated system that is taken by the learner both on the concept of language learning and the specific measures(Wen, 1995).

Many scholars try to classify language learning strategies from different perspectives, but academics still have different views. O’Mally and Chamot (1990) put forward three famous strategies from the perspective of cognitive psychology: metacognitive strategies, cognitive strategies, social or affective strategies. Oxford (1995) divides the strategy into direct and indirect strategies. Direct strategies include memory strategies, cognitive strategies, and compensation strategies. Indirect strategies included cognitive strategies, affective strategies and social strategies. Wen (1995) divided learning strategies into two categories: management strategies and language learning strategies. The former is related to the learning process, which is related to language learning materials.

Zhu (2016) suggested that mobile technology provides learners with the real situation of learners who travel across time and space to learn the same language as their native language, giving them full motivation to practice the target language, helping to create the necessary conditions for language learning, and achieving good learning outcomes.

Copyright(C) 2020 Yongjin Zhu et al.

doi: 10.18686/ahe.v4i10.2957

This is an open-access article distributed under the terms of the Creative Commons Attribution Non-Commercial License (http://creativecommons. org/licenses/by-nc/4.0/), which permits unrestricted non-commercial use, distribution, and reproduction in any medium, provided the original work is properly cited. 
According to the theory of digital learning and autonomous learning, mobile language learning has a great effect on the self-study, self-monitoring and self-evaluation of modern college students. Mobile language learning has a clear advantage in promoting the development of students' personality(Laurillard, 2007). In fact, the current college students have not moved to such a level of learning, most of them are leisure-oriented, no purpose, no strategy learning behavior. Survey shows that many college students' attention in English language mobile learning is easy to disperse. They do not have clear goals, and are easy to be outside the environment interference. Therefore, it is necessary to explore the current situation of university student's mobile language learning strategy(Zhang, 2012).

\section{Methodology}

\subsection{Research Questions}

What are the levels of mobile language learning strategy for private university student?

Is there significant difference in the mobile language learning strategy between male and female students?

\subsection{Questionnaire}

The questionnaire of language learning strategy (LLS) was originally invented by Oxford (1994), and was adapted by Chinese scholar Xiong Suchun (2014). The questionnaire includes five sub-constructs: meta-cognitive strategy, compensation strategy, cognitive strategy, memory strategy, affection strategy and social strategy. The questionnaire has 48 items to examine the student's beliefs in language learning strategy. Each item is answered by 5-point Liker scale from strongly agree (5) to strongly disagree (1). The students with higher scores show good uses of various strategies.

\subsection{Participants}

A total of 107 freshmen of non-English majors were selected from in a private university, including 59 females and 47 males. They have been learning English online for at least one year, and they have a training of mobile learning experience. And the data was collected at the end of the term and put into SPSS 22.0 for statistical analysis.

\section{Discussion and analysis}

\subsection{Reliability analysis}

The Cronbach alpha coefficient of the whole scale is 0.864 , and the sub-construct of the meta-cognitive strategy, cognitive strategy, memory strategy, compensation strategy, affection strategy and the social strategy is $0.728,0.687,0.762,0.643,0.532$, 0.763, which shows that the scale has a good reliability.

\subsection{The overall use of the various strategies}

According to Leong et al (2016), in five points of numerical rating scale, the mean value from 1-2.33 as low; 2.34 to 3.67 as moderate; 3.68 to 5 as high. From table 1, it showed the students' mobile language learning strategy was at a moderate level $(\mathrm{M}=2.885, \mathrm{SD}=0.390)$. Among the sub-strategy, all the sub-constructs were at a moderate level, while affection strategy and compensation strategy slightly higher than the rest strategies.

Table 1. descriptive statistics

\begin{tabular}{|c|c|c|}
\hline Constructs & Mean & Std. Deviation \\
\hline Meta-cognitive strategy & 2.796 & 0.554 \\
\hline Compensation strategy & 2.974 & 0.605 \\
\hline Cognitive strategy & 2.898 & 0.556 \\
\hline Memory strategy & 2.818 & 0.610 \\
\hline Affective strategy & 3.064 & 0.581 \\
\hline Social strategy & 2.805 & 0.720 \\
\hline Mobile LLS & 2.885 & 0.390 \\
\hline
\end{tabular}

\subsection{The gender analysis of mobile language learning strategies}

The table 2 showed that there is no significant difference between male and female student in the mean value of 
mobile language learning strategy $(t(105)=1.087, \mathrm{P}>0.05)$ and the sample in this study showed no significant difference in sub-constructs of meta-cognitive strategy $(t(105)=1.293, p>0.05)$, Compensation strategy $(t(105)=1.161, p>0.05)$, Cognitive strategy $(t(105)=1.008, p>0.05)$, Cognitive strategy $(t(105)=1.008, p>0.05)$, Memory strategy $(t(105)=0.617, p>0.05)$, Affection strategy $(t(105)=-0.120, p>0.05)$, Social strategy $(t(105)=0.983, \mathrm{P}>0.05)$. The results are in line with Xiong (2011) who studied the non-English major' online learning strategy and reported that no significant difference found between male and female students.

Table 2. the differences of language learning strategies for male and female students

\begin{tabular}{|c|c|c|c|c|c|c|}
\hline \multirow{2}{*}{} & \multicolumn{2}{|c|}{ Male students } & \multicolumn{2}{|c|}{ Female students } & \multirow{2}{*}{ MD } & $t$ \\
\cline { 2 - 6 } & $M$ & $S D$ & $M$ & $S D$ & & $t(105)=1.293, p>0.05$ \\
\hline Meta-cognitive strategy & 2.873 & 0.608 & 2.734 & 0.505 & 0.139 & $t(105)=1.161, p>0.05$ \\
\hline Compensation strategy & 2.985 & 0.663 & 2.966 & 0.559 & 0.019 & $t(105)=1.008, p>0.05$ \\
\hline Cognitive strategy & 2.958 & 0.628 & 2.849 & 0.491 & 0.109 & $t(105)=0.617, p>0.05$ \\
\hline Memory strategy & 2.859 & 0.593 & 2.786 & 0.627 & 0.073 & $t(105)=-0.120, p>0.05$ \\
\hline Affective strategy & 3.057 & 0.607 & 3.070 & 0.564 & -0.014 & $t(105)=0.983, \mathrm{P}>0.05$ \\
\hline Social strategy & 2.881 & 0.801 & 2.743 & 0.648 & 0.138 & $t(105)=1.087, \mathrm{P}>0.05$ \\
\hline Mobile LLS & 2.931 & 0.435 & 2.848 & 0.350 & 0.082 & \multirow{2}{*}{$t$} \\
\hline
\end{tabular}

\subsection{Discussion}

The results of the study showed that students had a moderate level of mobile language learning strategy and sub-strategies, which is not at a satisfactory level. This shows that the students are not familiar with the mobile learning mode and can not perform effectively in the mobile learning context. Among the six sub-strategies, affective strategy and compensation strategy were ranked the first two in the list, which showed that the interest in English and online learning is still very strong for the students compared with the traditional learning. The online learning reduce the classroom anxiety and also improve the selfefficacy from the peer contact and help. The high degree of compensation strategy means that students apply various skills to help their mobile English study. Social and meta-cognitive strategies ranked lower in the sub-strategies. Less social strategy is surprisingly to found in the study, which means that the students use the mobile devices to communicate in Chinese not in English study. The teacher may not involve the social APPs for English practice. The results also showed that the students use less meta-cognitive strategy in study. It means that students do not know how to make a plan for the mobile learning and can not evaluate the progress during the study accordingly.

From the results of the statistics, the male and female students were not found significant difference in the mobile strategy and sub-strategy, which is in consistent with the previous studies (Zuo, 2011). Many other studies showed that the female students had higher language learning strategy than male students (Zhu, 2016; Wu, 2009; Zhang, 2012).

\section{Conclusions}

The study showed that the students' mobile language learning in the private university is not well as expected and the they can not make good use of the mobile technology in the English study. More training of mobile learning is needed for the present students. Furthermore, students had a great interest in mobile learning. The course structure should be designed with mobile learning APPs so that students could perform the learning conveniently. In future, other factors such as the cultural difference, self-efficacy, test anxiety affecting the mobile language learning should be studied.

\section{References}

1. Leong MW, Chua YP, Kannan S. Relationship between principal technology leadership practices and teacher ict competence. Malaysian Online Journal of Educational Management 2016; 4(3): 13-36.

2. Oxford RL. Language learning strategies: What every teacher should know. New York: Newbury House; 1990.

3. Oxford RL, Nyikos M. Variables affecting choice of language learning strategies by University students. The Modern Language Journal 1997; 30(2).

4. Zhu YJ, Liu JM. A literature review of language learning strategy in west countries 2016; (1): 62-65. 